\title{
Clinical profile of pregnancy loss and placental histopathology at a University Hospital
}

\author{
Tamrakar SR ${ }^{1}$, Dhakal B ${ }^{2}$, Timalsina $\mathrm{N}^{1}$, Tripathi $\mathrm{P}^{1}$ \\ ${ }^{1}$ Department of Obstetrics and Gynecology, ${ }^{2}$ Department of Pathology Dhulikhel Hospital - Kathmandu University \\ Hospital, Kavre
}

Received: August 15, 2019

Accepted: November 5, 2019

\begin{abstract}
Aims: To review the clinical features of abortion and intrauterine fetal demise with histopathological findings in their placenta

Methods: A retrospective study conducted at Kathmandu University Dhulikhel Hospital from 2008 to 2018.

Results: A total of 431 placentas were examined over one decade. One third of them $(33.2 \%)$ had abortion. Mean age of the patients with abortion was $24.72 \pm 5.5$ years and that of intrauterine fetal demise (IUFD) was $25.36 \pm 5.4$ years ( $\mathrm{p}=0.2288$ ). Two thirds of patients with abortion presented with vaginal bleeding and/or lower abdominal pain; 73\% of IUFD presented with decreased fetal movement. Gross anomaly was the most common comorbid condition in abortion group while pre/post term, antepartum hemorrhage and PIH were the commoner conditions in IUFD group. In this study, 17.4\% abortion cases and $18.3 \%$ IUFD cases were with histopathologically proven infection.

Conclusions: Placental examination helps in revealing unseen pathologies in cases of poor obstetric outcomes in the form of abortion or fetal demise. The service provider should collect and provide required clinical information before studying the placenta to establish a hidden diagnosis

Keywords: abortion, chorioamnionitis, fetal demise, placenta.
\end{abstract}

Citation: Tamrakar SR, Dhakal B, Timalsina N, Tripathi P. Clinical profile of pregnancy loss and placental histopathology at a University Hospital. Nep J Obstet Gynecol. 2019;14(29):26-30. DOI:https://doi.org/10.3126/ njog.v14i2.28434.

\section{INTRODUCTION}

Fetus receives its nutritional requirements and gets its metabolic and immunological substances from the placenta. It is a principal organ for maintaining pregnancy and promoting fetal development.

Abortion is the commonest complication of pregnancy. Fifteen percent of recognized pregnancies terminate in spontaneous abortion. ${ }^{1}$ Vaginal bleeding affects approximately $15-20 \%$ of first trimester pregnancies with a foetal loss rate of approximately $50 \% .{ }^{2}$ It is well known that a high number of spontaneous abortions have genetic aberrations. The fetal developmental abnormality is associated with fetal part of placenta. ${ }^{3}$ There may be local, systemic and combined means of recognition of abnormal placental development and induction of abortion. ${ }^{4}$

Incidence of intrauterine fetal demise (IUFD) was
$2.13 \%$ in the year 2010 and $2011 . .^{5}$ The cause of IUFD can be maternal, fetal or placental. Several studies have shown placental pathology as a major contributor to IUFD, hence stressing the importance of its examination. ${ }^{6-8}$ When fetal death occurs, determining time of death in utero is always important and is based on macroscopic and histological changes of the placenta and fetus. ${ }^{9,10}$

The study of the placenta helps in revealing undiagnosed or unsuspected pathologies in cases of poor obstetric outcomes. ${ }^{11}$ Histopathological examinations (HPE) of placenta were regularly being done in abortion and IUFD cases in Dhulikhel Hospital (DH). This study was undertaken to relate the clinical features of abortion and IUFD with histopathological findings in their placenta among those treated in $\mathrm{DH}$. There were very limited publications related to

\section{CORRESPONDENCE}

Dr Suman Raj Tamrakar

Department of Obstetrics and Gynecology

Dhulikhel Hospital Kathmandu University Hospital, School of Medical Sciences

Email: drsuman3947@gmail.com; Phone: +977-9843530450 
placental findings from Nepal; and there was only one publication on the topic from $\mathrm{DH}^{12}$

Patients in early pregnancy with gestational age $<12$ weeks were enrolled into the study. The demographic parameters of the patients were noted. Center for Epidemiologic Studies Depression (CES-D) Scale was used to assess the presence of depression. ${ }^{10}$ Patients with a CESD score of 16 or greater was taken to be having depression. QOL was measured using the World Health Organization QOL BREF (WHOQOL BREF). ${ }^{11}$ WHOQOL BREF consists of 26 questions with a possible score of $1-5$ for each question. The instrument covers physical, psychological, social and environmental domains. The scores for each domain are added separately and transformed to a score of 0-100. Higher scores reflect better QOL. A validated Hindi version of WHOQOL BREF was used for Hindi speaking patients. ${ }^{12}$ Hindi and English version of WHOQOL BREF and English versions of CESD were used. Patients not conversant with Hindi and English were assisted by the investigators.

The data were analyzed using OpenStat software. The means of continuous variables were compared by Student's "t test", and the categorical variables were compared by Fisher's exact test. A value of $p<0.05$ was considered significant for Student's "t test" and Fisher's exact test. Pearson's correlation coefficient was calculated between depression and QOL. For correlations, $\mathrm{p}<0.01$ was considered statistically significant. The study was approved by the Institution Ethics Committee.

\section{METHODS}

This was retrospective study of clinical features of abortion and IUFD cases and histopathological findings in their placenta among those treated in DH from 2008 to 2018. Cases traced from the records at the Department of Obstetrics and Gynecology and Department of Pathology. Ethical clearance was taken from the hospital research committee. All data were analyzed by SPSS 16 packages. Frequency and mean were calculated. Chi-square test was used to analyze certain outcomes; p-value less than 0.05 was considered significant.

\section{RESULTS}

Mean age of the patients with abortion was $24.72 \pm 5.5$ years and that of IUFD was $25.36 \pm 5.4$ years $(\mathrm{p}=0.2288)$. From unadjusted demographic profile, there were $38(26.6 \%)$ abortions and $79(27.4 \%)$ IUFD of Tamang caste. One-third (32\%) of IUFD were associated with preterm, postterm, $\mathrm{PIH}$, breech, abnormal liquor, twins and IUGR; whereas the gross anomaly was present in $14 \%$ of abortions [Table-1].

Table-1: Comorbid conditions in patients with abortion and IUFD

\begin{tabular}{|ll|c|c|c|c|}
\hline \multirow{2}{*}{ Comorbid condition } & \multicolumn{2}{|l|}{$\begin{array}{l}\text { Abortion } \\
(\mathbf{n = 1 4 3 )}\end{array}$} & \multicolumn{2}{|c|}{ IUFD (n=288) } \\
\cline { 2 - 6 } & Frequency & \% & Frequency & $\%$ \\
\hline 1. & PIH & 4 & 2.8 & 11 & 3.8 \\
\hline 2. & IUGR & - & - & 7 & 2.5 \\
\hline 3. & Anomalies & 10 & 7.0 & 2 & 0.7 \\
\hline 4. & Anencephaly & 5 & 3.5 & - & - \\
\hline 5. & Hydrocephalus & - & - & 3 & 1.1 \\
\hline 6. & Hydrops & 5 & 3.5 & 4 & 1.4 \\
\hline 7. & $\begin{array}{l}\text { Down's } \\
\text { syndrome }\end{array}$ & - & - & 1 & 0.3 \\
\hline 8. & $\begin{array}{l}\text { Abnormal } \\
\text { liquor }\end{array}$ & 3 & 2.1 & 9 & 3.2 \\
\hline 9. & APH & - & - & 12 & 4.2 \\
\hline 10. & Twin pregnancy & - & - & 7 & 2.5 \\
\hline 11. & Pre term & - & - & 23 & 8.0 \\
\hline 12. & Post term & - & - & 12 & 4.2 \\
\hline 13. & CPD & - & - & 4 & 1.4 \\
\hline 14. & Cord prolapsed & - & - & 5 & 1.8 \\
\hline 15. & Hand prolapsed & - & - & 3 & 1.1 \\
\hline 16. & Transverse lie & - & - & 7 & 2.5 \\
\hline 17. & Breech & - & - & 10 & 3.5 \\
\hline 18. & Nuchal cord & - & - & 4 & 1.4 \\
\hline 19. & Single uterine & - & 5 & 1.8 \\
\hline 20. & Morbid & - & 119 & 41.7 \\
\hline
\end{tabular}

Besides, there were 29 missed abortion cases, three cervical incompetence and two molar cases. There were seven hypothyroidism, three UTI, three vaginitis, two PTB and each case of TTP, VDRL positive, dermoid cyst and fibroid. Twenty cases were medically terminated for different reasons. There were four previous cesarean cases; additional twelve and two cases underwent LSCS and hysterotomy respectively; and $73.4 \%$ IUFD cases presented with decreased fetal movement for at least one day. Infection, chorangiosis and infarction were the common abnormal findings detected in placental examination in case of poor obstetric outcome [Table-2]. 
Table-2: HPE findings in abortion and IUFD

\begin{tabular}{|l|l|c|l|c|}
\hline \multirow{2}{*}{ HPE } & \multicolumn{2}{|l|}{ Abortion (n=143) } & \multicolumn{2}{l|}{ IUFD (n=288) } \\
\cline { 2 - 5 } & Frequency & $\%$ & Frequency & $\%$ \\
\hline Normal & 115 & 80.4 & 213 & 74.0 \\
\hline Infection & 25 & 17.4 & 53 & 18.3 \\
\hline Chorioamnionitis & 10 & 7.0 & 24 & 8.3 \\
\hline $\begin{array}{l}\text { Extraplacental } \\
\text { membranitis }\end{array}$ & 11 & 7.6 & 21 & 7.3 \\
\hline $\begin{array}{l}\text { Funisitis/umbilical } \\
\text { cord perivasculitis }\end{array}$ & 3 & 2.1 & 6 & 2.1 \\
\hline Villitis & 1 & 0.7 & 2 & 0.6 \\
\hline Chorioangiosis & - & - & 10 & 3.5 \\
\hline Infarction & 3 & 2.1 & 8 & 2.8 \\
\hline Chorioangioma & - & - & 3 & 0.9 \\
\hline $\begin{array}{l}\text { Intervillous } \\
\text { haemorrhage }\end{array}$ & - & - & 1 & 0.3 \\
\hline Total & 143 & 100.0 & 288 & 100.0 \\
\hline
\end{tabular}

Certain pathologies were notified in pregnancy with one of the clinical problems even though this was not statistically significant [Table-3].

Table-3: Association of clinical conditions and pathological findings

\begin{tabular}{|l|l|l|}
\hline $\begin{array}{l}\text { OBSTETRIC } \\
\text { CONDITIONS }\end{array}$ & Abnormal HPE reports & Normal \\
\hline Polyhydramnios (2) & - & 2 \\
\hline Oligohydramnios (10) & Amnionitis (2), infarction (1) & 7 \\
\hline Twin pregnancy (7) & Infarction (1) & 6 \\
\hline Abruptio/APH (12) & Amnionitis (3), single UA (1) & 8 \\
\hline Hand prolapsed (3) & Chorangiosis (1) & 2 \\
\hline Cord prolapsed (5) & Amnionitis (2), chorangiosis (2) & 1 \\
\hline Transverse lie (7) & Amnionitis (2), chorangiosis(2) & 3 \\
\hline Postterm (12) & Funisitis (3) & 9 \\
\hline Preterm (23) & $\begin{array}{l}\text { Chorio/amnionitis (4), chorangioma } \\
\text { (1), single UA (1) }\end{array}$ & 18 \\
\hline PET (15) & Infarction (1), single UA (1) & 13 \\
\hline IUGR (7) & Infarction (3) & 4 \\
\hline Rh negative (2) & Amnionitis (1) & 1 \\
\hline Hypothyroidism (1) & - & 1 \\
\hline VDRL positive (1) & - & 1 \\
\hline FETAL CONDITIONS & & 3 \\
\hline Down's syndrome (1) & - & 3 \\
\hline Hydrocephalus (3) & - & $\begin{array}{l}\text { Membranitis (1), infarction (1) } \\
\text { (1), infarction (1) }\end{array}$ \\
\hline Anencephaly (5) & $\begin{array}{l}\text { Chorangiosis (1), infarction (1), } \\
\text { single UA (1) }\end{array}$ & 9 \\
\hline Hydrops (9) & & 3 \\
\hline Other anomalies (12) & 3 \\
\hline
\end{tabular}

\section{DISCUSSION}

According to World health Organization, intrauterine fetal demise encompasses any abortion or fetal demise prior to expulsion from its mother, and recommends different protocols according to gestational age.

Both the first trimester abortion and second trimester fetal demise are classified differently in different literatures. Third trimester fetal demise is of more concern as the extrauterine fetal survival is increasingly better in this trimester. ${ }^{13-15}$ Implantation anomalies can lead to neurological damage and increased risk of fetal loss. ${ }^{16,17}$ The gestational age, placental lesions and placentation are determining factors for fetal complications. ${ }^{11}$

According to Nepal Demographic and Health Survey (NDHS) 2016, of total pregnancies, $81 \%$ were live births, $9 \%$ were induced abortions, $9 \%$ were miscarriages and $1 \%$ was fetal deaths. The proportion of pregnancies ending in abortions and fetal deaths among under 20, 20-34 and 35-49 years were 9.5, 8.5 and 14.3; and 1.5, 1.2 and 2.7 respectively.18 There may be many more abortions (30-40\% of all conceptions) in early and unrecognized pregnancies. ${ }^{1}$

Incidence of intrauterine fetal demise was $2.13 \%$ in $\mathrm{DH} .{ }^{5}$ Shrestha J et al, found the rate of fetal death as $2.2 \%$ in Western Nepal. ${ }^{19}$

In $\mathrm{DH}$, the mean age of patient with abortion at the presentation was $23.96 \pm 3.89$ years $(n=104)$ (Kayastha B, 2015, unpublished data). And that of mothers with abortion was $24.72 \pm 5.5$ years in this study ( $\mathrm{p}=0.2288)$. In a study of 111 abortion cases, mean age was $25.09 \pm 5.58$ years; ${ }^{12}$ and majority (94\%) cases with IUFD were in 21-30 years of age group. ${ }^{20}$

Mothers in fetal death group were slightly older than mothers of live-born infants $(25.47 \pm 5.64$ years vs $23.62 \pm 4.31$ years, $p$ value $=0.000$ ). A slightly higher proportion of women in the stillbirth group were of Tamang caste $(28.9 \%, \mathrm{p}=0.011) .{ }^{5}$ In this study, mean age of mothers with IUFD was $25.36 \pm 5.4$ years and of Tamang caste was $27.4 \%$.

The impaired placental function in terms of abnormal placental morphology or histology accounts for the fetal and neonatal complications. The pathology of spontaneous abortions is an important aspect of understanding the etiology.1Hence the obstetrician should collect relevant clinical information and a list of queries; and the pathologist is responsible for placenta examination to correlate pathological findings with clinical implications..$^{21,22}$ 
Abortion cases usually present with vaginal bleeding and lower abdominal pain. Vaginal bleeding in first trimester occurs in about $25 \%$ of the pregnancies and $5 \%$ of pregnancies in second trimester. ${ }^{2}$ In this study, two thirds of patients with abortion presented with vaginal bleeding and/or lower abdominal pain. The mean gestational age at the time of bleeding for the case was $11.36 \pm 5.3$ weeks (Kayastha B, 2015, unpublished data).

In a study ( $\mathrm{n}=436)$, the mean age of the pregnant ladies came with decreased fetal movement was $24.11 \pm 3.85$ years. And $82.6 \%$ complained of decreased fetal movement for 24 hours (maximum 10 days) (Manandhar S, 2016, unpublished data). In this study, the mean age of patient with IUFD was $24.72 \pm 5.5$ years. These cases presented with decreased fetal movement of one day (at least) $(73.4 \%)$, prelabor rupture of membranes (watery discharge) (17\%), pain lower abdomen and abnormal presentations (8.3\% each) and bleeding per vaginum or abnormal vaginal discharge (3.1\% each).

The ascending/adjacent infection as a subclinical condition present in $20 \%$ of cases. Histological analysis allows the diagnosis of acute/subacute chorioamnionitis and should be classified. This condition may be associated with maternal hypertension, diabetes, IUGR, oligohydramnios, hydrops fetalis and poor perinatal evolution. ${ }^{23,24}$ In this study $17.4 \%$ abortion cases and $18.3 \%$ IUFD cases were with histopathologically proven infection.

Massive chronic intervillositis is a medical condition also singularly diagnosed with histology and is associated with IUGR and fetal death and commonly described in recurrent abortions. In $70 \%$ of cases, this condition is present simultaneously with chronic villitis and is related to prematurity and neurological injury. ${ }^{25}$

Different histological lesions in chorionic villi included hydropic change, number of vessels, patency of vessels, fibrosis, fibrinoid degeneration and Hofbauer macrophages. Fibrosis is the final common pathway for nearly all forms of disease that progress towards end stage organ failure. Fibrinoid degeneration is the deposition of fibrinoid material, initially external to basement membrane of syncytiotrophoblast. Later it appears in the villous stroma. ${ }^{27}$ Chorangioma (CA), chorangiosis $(\mathrm{CH})$ and chorangiomatosis $(\mathrm{CM})$ are incompletely understood and overlapping villous capillary (VC) lesions believed by some to be related to hypoxia. ${ }^{28}$ Chorangiosis has correlation with perinatal complications.

Sarin et al showed that intravillous fibrin deposition was observed in three times more in spontaneous abortions (46.1\%) and nine times more hyaline change in spontaneous abortions $(67 \%){ }^{28}$ The study has revealed that inflammation and fibrin deposition are the major findings in the histopathological examination of decidua. ${ }^{12}$

Massive perivillous fibrin deposition is the main diagnostic features of maternal floor infarction, a placental lesion with incidence of $0.5 \%$. Extensive placental infarction is usually seen in placentae from preeclamptic mothers when there is a vascular abnormality which predisposes to thrombosis. Placental infarction can be associated with fetal intrauterine growth retardation (IUGR), microcephaly and neurological complications..$^{29,30}$

In a study of 65 IUFD cases, Patil NJ et al found placenta related death in $77 \%$ with chorioamnionitis (55.5\%), utero-placental insufficiency (UPI) $22.2 \%$. and twin-twin transfusion syndrome. Fetal causes included congenital anomalies (anencephaly; twochambered heart) and Rh incompitability. Causes not directly related to placenta showed chorangiosis and amnion nodosum..$^{20}$ In this study, varied form of HPE findings in abortion and IUFD were found.

\section{CONCLUSIONS}

Placental examination helps in revealing unseen pathologies in cases of poor obstetric outcomes in the form of abortion or fetal demise; and it requires adequate clinical information to correlate the pathology. Histopathological examination of placenta in case of poor obstetric outcome should be made mandatory.

\section{CONFLICT OF INTEREST}

No conflict of interest was declared by the authors. 


\section{REFERENCES}

1. Crum CP. The Female Genital Tract. In: Ramzi S. Cotran Vinay Kumar, Tucker Collins. Pathologic Basis of Disease.7th ed. Philadelphia: WB. Saunders. 2004;1079-80.

2. Abu-Yousef MM, Bleider JJ, Williamson RA, Weiner CP Subchorionic hemorrhage: Sonographic diagnosis and clinical significance. Am J Roentgenol. 1987;149:737-40.

3. Lesley R, Katy C. Sporadic \& Recurrent Miscarriage. In Geoffrey Chamberlain, Philip J Steer. Turnbull's Obstetrics 3rd ed. Philadelphia: Churchill Livingstone. 2001;117-25.

4. Novak RF. A Brief Review of Anatomy, Histology and ultrastructure of the full term placenta. Arch Pathol Lab Med. $1991 ; 115: 654-9$

5. Tamrakar SR, Chawla CD. Intrauterine foetal death and its probable causes: Two year experience in Dhulikhel Hospital - Kathmandu University Hospital. Kathmandu Univ Med J. 2012;10(4):44-8

6. Kidron D, Bernheim J, Aviram R. Placental findings contributing to fetal death, a study of 120 stillbirths between 23 and 40 weeks gestation. Placenta. 2009;30(8):700-4.

7. Korteweg FJ, Erwich JHM, Holm JP, Ravise JM, Meer J, Veeger JGM, et al. Diverse placental pathologies as the main causes of fetal death. Obstet Gynecol. 2009;114(4):809-17.

8. Hayati AR, Khong TY, Zainul R. The usefulness of limited placental sampling in stillbirths. Malaysian $\mathrm{J}$ Pathol. 1998;20(2):99-102.

9. Jacques SM, Qureshi F, Johnson A, Alkatib AA, Kmak DC. Estimation of time of fetal death in the second trimester by placental histopathological examination. Pediatr Dev Pathol. 2003;6:226-32.

10. Moore IE. Macerated stillbirth. Fetal and Neonatal Pathology. 2011;224-39.

11. Nogueira R, Pinto-Ribeiro, Pereira SM and Valente F. Macroscopic and histopathological study of the placenta - an essential resource in litigation processes. J Clin Res Bioeth. 2015;6:247. doi:10.4172/2155-9627.1000247

12. Makaju R, Shrestha S, Sharma S, Dhakal R, Bhandari S, Shrestha A, et al. Histopathological changes in the chorionic villi and endometrial decidual tissues in the product of conception of spontaneous abortion cases. Kathmandu Univ Med J. 2015;52(4):357-60.

13. Petitti DB. The epidemiology of fetal death. Clin Obstet Gynecol. 1987;30:253-8.

14. Wang X, Chen C, Wang L, Chen D, Guang W, French J. Conception, early pregnancy loss, and time to clinical pregnancy: a population-based prospective study. Fertil Steril. 2003;79:577-84.

15. Wilcox AJ, Weinberg CR, O'Connor JF, Baird DD, Schlatterer JP, Canfield RE, et al. Incidence of early loss of pregnancy. N Engl J Med. 1988;319:189-94.

16. Adams-Chapman I, Vaucher YE, Bejar RF, Benirschke $\mathrm{K}$, Baergen RN. Moore TR. Maternal floor infarction of the placenta: association with central nervous system injury and adverse neurodevelopmental outcome. J Perinatol. 2002;22(3):236-41. DOI:10.1038/sj.jp.7210685

17. Ohyama M, Itani Y, Yamanaka M, Goto A, Kato K, Ijiri $\mathrm{R}$, et al. Re-evaluation of chorioamnionitis and funisitis with a special reference to subacute chorioamnionitis. Hum Pathol. 2002;33:183-90.

18. Ministry of Health, Nepal; NEW ERA; and ICF. 2017. Nepal Demographic and Health Survey 2016. Kathmandu, Nepal. 151 and 194.

19. Shrestha J, Shrestha R, Gurung S. Determining the associated factors and causes according to relevant condition at death: an experience from Pokhara, Nepal. J Nobel Med Col. 2017;2:11:58-65. DOI: http://dx.doi.org/10.3126/jonmc. v6i2.19572

20. Patil NJ, Shukla DB, Dhawan S. Placental pathology in intra: uterine foetal deaths. Int $\mathrm{J}$ Reprod Contracept Obstet Gynecol. 2016;5(7):2250-3. DOI: http://dx.doi. org/10.18203/2320-1770.ijrcog20162103

21. Roberts DJ, Oliva E. Clinical significance of placental examination in perinatal medicine. J Mater Fetal Neonatal Med. 2006;19:255-64.

22. Al-Adnani M. Sebire NJ. The role of perinatal pathological examination in subclinical infection in obstetrics. Best Pract Res Clin Obstet Gynaecol. 2007;21:505-21.

23. Kim CJ, Romero R, Chaemsaithong P, Chaiyasit N, Yoon BH, Kim YH. Acute chorioamnionitis and funisitis: definition, pathologic features, and clinical significance. Am J Obstet Gynecol. 2015;213:S29-52. DOI: 10.1016/j.ajog.2015.08.040

24. Ericson JE, Laughon MM. Chorioamnionitis: implications for the neonate. Clin Perinatol. 2015;42:155-65.

25. Doss BJ, Greene MF, Hill J, Heffner LJ, Bieber FR, Genest DR. Massive chronic intervillositis associated with recurrent abortions. Hum Pathol. 1995;26:1245-51.PMID: 7590700

26. Joshi VV. Handbook of Placental Pathology. New York: IGaku-Shoin Medical Publishers. 1994:128 pages.

27. Ogino S. Raymond WR. Villous capillary lesions of the placenta: distinctions between chorangioma, chorangiomatosis, and chorangiosis. Human Pathology. 2000;31(8):945-54. DOI: 10.1053/hupa.2000.9036

28. Sarin AR, Kaur B, Modi S, Popli R. Histopathological changes in placenta in early pregnancy wastage. Indian J Matern Child Health. 1993;4:75-7

29. Vinnars MT, Vollmer B, Nasiell J, Papadogiannakis N, Westgren $M$. Association between cerebral palsy and microscopically verified placental infarction in extremely preterm infants. Acta Obstet Gynecol Scand. 2015;94:976-82.

30. Furuta K, Tokunaga S, Furukawa S, Sameshima H. Acute and massive bleeding from placenta previa and infants' brain damage. Early Hum Dev. 2018;90:455-8 